Review Article

\title{
Gnathic Bones and Hyperparathyroidism: A Review on the Metabolic Bony Changes Affecting the Mandible and Maxilla in case of Hyperparathyroidism
}

\author{
Hazim Mahmoud Ibrahem \\ Department of Basic Sciences, Al-Mustansiriyah University, College of Dentistry, Baghdad, Iraq \\ Correspondence should be addressed to Hazim Mahmoud Ibrahem; hazimahmoud56@yahoo.com
}

Received 8 November 2019; Revised 5 June 2020; Accepted 22 June 2020; Published 9 July 2020

Academic Editor: Noureddin Nakhostin Ansari

Copyright ( 2020 Hazim Mahmoud Ibrahem. This is an open access article distributed under the Creative Commons Attribution License, which permits unrestricted use, distribution, and reproduction in any medium, provided the original work is properly cited.

\begin{abstract}
Parathyroid glands secrete the parathyroid hormone that plays an essential role in bone remodeling. Excessive production of parathyroid hormone causes a common metabolic bone disorder known as hyperparathyroidism that is classified into primary, secondary, or tertiary. In hyperparathyroidism, the late bony complication is manifested as a giant cell osteolytic lesion called "brown tumor." Primary hyperparathyroidism is usually a sporadic disorder, but in minority of cases it occurs in inherited forms, and one of these forms is the hyperparathyroidism-jaw tumor syndrome, which is characterized by primary hyperparathyroidism and ossifying fibroma in the mandible and/or maxilla.
\end{abstract}

\section{Introduction}

There are 4 parathyroid glands located behind the thyroid gland which secrete parathyroid hormone "parathormone" (PTH) which maintains a proper calcium balance in bloodstream and in tissues that require calcium for their physiological functions. Excessive secretion of PTH and prolonged exposure of bone to PTH result in the metabolic bone disorder known as hyperparathyroidism (HPT) [1]. Brown tumor is comparatively an uncommon non-neoplastic osteolytic lesion of bones that appears in advanced stage of hyperparathyroidism [2]. Association of primary hyperparathyroidism and ossifying fibroma of the jaw is seen in a rare hereditary syndrome referred as hyperparathyroidismjaw tumor (HPT-JT) [3].

This review focuses on the gnathic metabolic bone changes that result from increased parathyroid hormone secretion in case of hyperparathyroidism.

\section{Review}

2.1. Hyperparathyroidism. Hyperparathyroidism could be described as an endocrine disorder resulting from increased secretion of parathyroid hormone and is characterized by hypercalcemia due to increased mobilization of calcium from bone to circulation [4]. HPT is classified into the following clinical forms:

(1) Primary HPT (PHPT) which is either of a nonfamilial (sporadic) form representing about $90-95 \%$ of all PHPT or familial inherited form representing $5-10 \%$ of PHPT [5].

(2) Secondary HPT which results from a primary condition producing hypocalcemia such as rickets, osteomalacia, vitamin $\mathrm{D}$ deficiency, prolonged hypocalcemia caused by chronic renal failure, and long-term dialysis $[6,7]$.

(3) Tertiary HPT which results from long-standing secondary HPT [8]. 
(4) A fourth type of HPT (because of ectopic parathyroid gland) which is thought to arise in patients with malignant diseases [9].

Clinically, HPT shows variation in signs and symptoms including bone fractures, kidney stones, peptic ulcers, easy fatigue, sense of weakness, depression, anxiety, and myocardial, valvular, and vascular calcification $[10,11]$.

\subsection{Metabolic Bone Changes in Hyperparathyroidism. In} HPT, bone metabolic changes are considered as the late manifestation, and these include bone erosion, bone resorption, and localized bone cystic lesions named as "brown tumors." Together, all these features are described as osteitis fibrosa cystica $[12,13]$.

2.2.1. Brown Tumor. Brown tumor (BT) is non-neoplastic giant cell lesion that appears in advanced stage of hyperparathyroidism. It represents a giant cell reparative cellular phenomenon that involves areas with intense bone resorption due to the effect of high circulating PTH levels [14].

The real global incidence of brown tumor is not well estimated [15]. With the development of imaging and laboratory screening methods, hypercalcemia in cases of HPT can often be discovered in early stages resulting in a decline in the frequency of brown tumors [16]. All the information related to the prevalence and incidence of brown tumors are dated at the end of 1990s and have not been updated, and these information indicated that brown tumor frequency is of 3-4\% in primary hyperparathyroidism and $1.5-1.75 \%$ in secondary hyperparathyroidism [17]. In maxillofacial region, more than $70 \%$ of the lesions affect the mandible while very few cases have been reported in the maxilla [18].

The incidence of brown tumor is more in people older than 50 , and the female: male ratio is $3: 1$ [19].

The term "tumor" is a misnomer because the lesion does not have a neoplastic potential, and any bone may be involved by this lesion, though the common locations are the long bones, ribs, clavicle, spine, extremities, pelvic girdle, mandible, and maxilla with the mandible being more affected than maxilla $[20,21]$.

Pathological increased level of PTH in HPT causes increased resorption of bone trabeculae in a "tunneling" or "dissecting" pattern which leads to the enlargement of marrow space causing weakening of the bone, and this weakening will lead to microfractures and intraosseous microhemorrhages. Microfractures, intraosseous bleeding, and tissue degeneration cause influx of macrophages ending with hemosiderin-loaded macrophages, giant cells, and fibroblast filling the newly formed small osteolytic cysts. These small cysts fuse together giving the characteristic brown color of this lesion [22, 23].

Clinical symptoms caused by brown tumors depend on their location and size; they range from small asymptomatic lesion, discovered accidentally by radiological examination, to a large locally destructive lesion resulting in a variety of symptoms that are mostly related to facial deformation and disfiguration, such as difficulty in chewing, talking, and breathing. Intraorally, it presents as an expansile bone lesion (localized or diffuse); it causes abnormal occlusion due to mobility and displacement of teeth in the affected region $[24,25]$.

Histopathological examination reveals a benign process. Brown tumor is considered as a kind of giant cell lesion that presents as an osteolytic lesion of the bone. It is nonencapsulated and characterized by multiple giant cells mixed with vascular fibrous tissue stroma, spindle-shaped mononuclear cells, haemosiderin-laden macrophages, and matrix containing large amount of haemosiderin [26].

The radiological appearance of the lesions may vary according to the stage of HPT. In some cases, they are poorly defined, while others have a sclerotic margin [27]. In hyperparathyroidism, the radiographic image of the skull shows "saltand-pepper" appearance due to the trabecular bone resorption [28]. Brown tumors appear as well demarcated unilocular or multilocular radiolucencies with the bone trabecular pattern showing a "ground-glass" appearance. Oral radiographic manifestations associated with BTs include root resorption with generalized loss of lamina dura surrounding the roots of the teeth, loss of cortication around the inferior alveolar canal and maxillary sinus, and alteration of the trabecular pattern of the jaws $[29,30]$. On CT scan, brown tumors mostly appear as a lytic expansive lesion, without periosteal reaction [31]. On magnetic resonance imaging, the image demonstrates hypo- or isointense on T1 and T2-weighted imaging, as well as a strong homogenous enhancement with gadolinium [32]. Thus, when a patient, especially between the age of 20-40 years, presents with unexplained osteolytic radiolucent bone lesions, radiologists should consider PHPT in differential diagnosis.

In differential diagnosis of brown tumor with a solitary bone lesion, it may be difficult to differentiate from aneurysmal bone cyst, true giant cell tumor, solitary bone cyst, cherubism, or giant cell reparative granuloma. In cases of multiple brown tumors, the differential diagnosis includes multiple nonossifying fibroma, osteolytic metastasis, multiple myeloma, multiple bone cysts, Langerhans' cell histiocytosis, metabolic osteopathy, and fibrous dysplasia [33].

Brown tumor fine needle aspiration smears show scattered giant and mononuclear cells. The mononuclear cells have scanty ill-defined cytoplasm with irregular margins and monomorphic nuclei. The giant cells are very scanty in number and may vary in size [34].

Management of brown tumor is often directed toward the normalization of PTH level through the management of the underlying cause of HPT, and this frequently results in regression and resolution of these lesions without the need of extensive surgical intervention; however, surgical treatment may be required in refractory cases or in large disfiguring symptomatic lesions that cause bone weakening $[35,36]$. Surgical excision of the jaw lesion, when required, is usually done after parathyroid surgery [37].

2.3. Hereditary Hyperparathyroidism Syndromes. Most cases of primary hyperparathyroidism are sporadic, but in less than $10 \%$, they are familial inherited in nature which are usually present as an autosomal dominant trait, namely, 
multiple endocrine neoplasia type 1 (MEN1), MEN2A, MEN4, familial hypocalciuric hypercalcemia (FHH), neonatal severe hyperparathyroidism (NSHPT), autosomal dominant moderate hyperparathyroidism (ADMH), hyperparathyroidism-jaw tumor syndrome (HPT-JT), and familial isolated hyperparathyroidism (FIHPT) [38].

HPT-JT Syndrome is a rare autosomal dominantly inherited disorder characterized by primary HPT caused mostly by parathyroid adenomas and fibro-osseous tumors of the mandible and/or the maxilla named ossifying fibroma [39].

HPT-JT is a complex disease with clinical diversity and long time span; it is characterized by two main categories, hyperparathyroidism and ossifying fibromas of the mandible or maxilla. Moreover, this disease could be associated with Wilms tumor, renal hamartomas, and kidney lesions [40]. The onset of primary hyperparathyroidism in HPT-JT syndrome occurs in late adolescence or early adulthood with average age 32 years [41].

Pathogenetically, HPT-JT syndrome is usually caused by mutations in the tumor suppressor gene named CDC73 (Cell Division Cycle Protein 73) gene which is previously known as HRPT2 (Hereditary Parathyroid Type 2) gene [42]. Germline mutations in CDC73 have been identified in most (about 50-75\%) of HPT-JT kindreds [43]. Physiologically, CDC73 gene is responsible for the synthesis of nuclear protein parafibromin which is responsible for the regulation of cell growth and proliferation having antiproliferative properties, enhancing cell cycle arrest [44]. Female individuals with this syndrome may have benign or malignant uterine tumors [45]. HPT-JT is clinically diagnosed in individuals with any of the following characteristics: (1) PHPT and ossifying fibroma of the jaw, (2) PHPT and a close relative with HPT-JT, or (3) ossifying fibroma of the jaw and a close relative with HPT-JT [46].

\subsubsection{Associate Jaw Lesion (Ossifying Fibroma) in Hyper-} parathyroidism-Jaw Tumor Syndrome. The jaw lesion associated with HPT-JT syndrome has been reported to be histologically distinct from BT and does not resolve after parathyroidectomy, and it falls within the category of fibroosseous lesions and identifies as ossifying fibroma of the mandible and/or maxilla [47].

It occurs in $25-50 \%$ of individuals with HPT-JT, and these jaw tumors may occasionally precede the development of hyperparathyroidism in HPT-JT patients by several decades [48].

(1) Ossifying Fibroma. Ossifying fibroma is a rare benign fibro-osseous neoplasm affecting jaw bone and is characterized by replacement of normal bone by a combination of fibrous tissue and newly formed calcified tissues of bone and/or cementum-like material [49].

Ossifying fibroma occurrence begins between the ages of 10 and 20 years, and females are affected more often than males [50].

Ossifying fibromas mostly involve only one side of either the mandible or maxilla, and the mandible is more affected than the maxilla. Multifocal ossifying fibromas are much less common [51]. Regarding the histogenesis and pathogenesis of $\mathrm{OF}$, the majority of authors affirm that $\mathrm{OF}$ is periodontal in origin in which there is excessive proliferation of the mesenchymal cells of periodontal ligament. On the other hand, two studies suggest that the histogenesis of OF consist of two possible origins: first is periodontal in origin in which there is excessive proliferation of mesenchymal cells of the periodontal ligament and second is nonperiodontal in origin resulting from metaplastic process occurring in the connective tissue cells, the former being more common $[52,53]$. Error in the process of odontogenesis may cause extensive mesenchymal cellular induction of periodontal tissue with the formation of new fibrous tissue, bone, and cementum, and those will lead to the development of ossifying fibroma in the jaw bone [54]. Precise triggering factors are still not known, but some suggested some factors that include trauma, previous extractions, and pre-existence of periodontitis [55].

Pimenta et al.[56] suggested that some cases of OF may arise as a result of somatic mutation in HRPT2 due to haploinsufficiency of the gene. de Mesquita Netto et al. [57] concluded that the contribution of HRPT2 gene inactivation to the pathogenesis of OF is marginal at best and may be limited to the progression of the tumor rather than its initiation. Chen et al. [58] suggested that CDC73 mutations are rare in sporadic OFs of the jaws, yet CDC73 may play a role in the pathogenesis of a small subset of tumors.

Clinically, OF can present as a single solitary lesion or rarely as multiple lesions and may occasionally be bilateral/ multifocal $[59,60]$. These tumors are slowly growing lesions that can grow to a size that causes the expansion of the buccal and lingual plates; they can also cause early tooth displacement and disruption in normal dentition, but typically, they do not cause root resorption and the lamina dura of involved teeth is usually missing; furthermore, the lesion may grow to an extensive size pressing on the adjacent vital structures such as nerves causing pain and paresthesia [61-63].

Histologically, ossifying fibroma is described as a demarcated and occasionally encapsulated benign neoplasm characterized by the replacement of normal bone by fibrous tissue and varying amount of newly formed bone and/or cementum-like material [64].

Radiological finding suggests that the lesion is usually well circumscribed having a sclerotic rim and demarcated from surrounding bone and shows a centrifugal growth pattern rather than a linear one [65]. On plain radiographic film, the appearance of OF depends on the stage of maturation of the lesion and the amount of mineralized tissue within the tumor; lesion may appear completely radiolucent, radiolucent with variable degrees of radiopacity, or totally radiopaque [66]. On CT, ossifying fibroma usually reveals a sharply circumscribed eggshell-thin rim of bone surrounding a lytic area and on MR T1-weighted imaging; they return low to intermediate signal, the low signal areas reflecting the osseous component. On T2-weighted sequences, ossified areas appear with low signal, while fibrous tissue exhibits a hypointense signal. The thick outer layer of 
the tumor enhances following administration of contrast [67]. The differential diagnoses involving radiolucent lesions include odontogenic cysts, ameloblastoma, central giant cell lesions, chronic apical periodontitis, and idiopathic bone cavity. Radiopaque lesions include fibrous dysplasia complex odontoma, idiopathic osteosclerosis, and cementoblastoma. Mixed lesions include osteoblastoma, calcifying cystic odontogenic tumor, and calcifying epithelial odontogenic tumor [68].

The treatment plan of ossifying fibroma is individualized and case specific, depending on the size, location, and nature and growth behavior of the lesion. Generally, the management comprises complete surgical excision of the jaw lesion till the healthy bone margin is reached, and bone grafting and reconstruction is to be considered when necessary, and this should be done after removal of the parathyroid lesions (parathyroidectomy) [69, 70]. OF tends to recur with incomplete resection, and the recurrence is more common in younger patients; thus, orthopantomography of the face should be preferably performed once in every three years to detect any possible changes with follow-up period of at least 10 years [71, 72].

Prognosis of ossifying fibroma appears to be good. There is no evidence suggesting that $\mathrm{OF}$ can undergo malignant potential [73].

\section{Conclusion}

Hyperparathyroidism is a metabolic endocrine disorder characterized by increased bone turnover. The osteolytic jaw bone lesions associated with hyperparathyroidism make up diverse disorders of which some are neoplastic or nonneoplastic and hereditary or nonhereditary, and some affect the elderly while others affect the adolescent and young adult.

\section{Conflicts of Interest}

The author declares that there are no conflicts of interest.

\section{References}

[1] C. G. Arthur and E. H. John, Textbook of Medical Physiologypp. 978-995, Elsevier Saunders, Philadelphia, PA, USA, 11th edition, 2006.

[2] A. D. Shetty, J. Namitha, and L. James, "Brown tumor of mandible in association with primary hyperparathyroidism: a case report," Journal of International Oral Health: JIOH, vol. 7, no. 2, pp. 50-52, 2015.

[3] A. Guerrouani, A. Rzin, and K. El Khatib, "Hyperparathyroidism-jaw tumour syndrome detected by aggressive generalized osteitis fibrosa cystica," Clinical Cases in Mineral and Bone Metabolism, vol. 10, no. 1, pp. 65-67, 2013.

[4] J. H. Choi, K. J. Kim, Y. J. Lee et al., "Primary hyperparathyroidism with extensive Brown tumors and multiple fractures in a 20-year-old woman," Endocrinology and Metabolism, vol. 30, no. 4, pp. 614-619, 2015.

[5] F. Marini, L. Cianferotti, F. Giusti, and M. L. Brandi, "Molecular genetics in primary hyperparathyroidism: the role of genetic tests in differential diagnosis, disease prevention strategy, and therapeutic planning. A 2017 update," Clinical
Cases in Mineral and Bone Metabolism, vol. 14, no. 1, pp. 60-70, 2017.

[6] P. Lips, "Vitamin D deficiency and secondary hyperparathyroidism in the elderly: consequences for bone loss and fractures and therapeutic implications," Endocrine Reviews, vol. 22, no. 4, pp. 477-501, 2001.

[7] I. H. De Boer, I. Gorodetskaya, B. Young, C. Y. Hsu, and G. M. Chertow, "The severity of secondary hyperparathyroidism in chronic renal insufficiency is GFR-dependent, race-dependent, and associated with cardiovascular disease," Journal of the American Society of Nephrology, vol. 13, no. 11, pp. 2762-2769, 2002.

[8] N. K. Yuen, S. Ananthakrishnan, and M. J. Campbell, "Hyperparathyroidism of renal disease," The Permanente Journal, vol. 20, no. 3, pp. 15-127, 2016.

[9] S. Doshi, A. Vadi, A. Mahajan, and T. Nagpal, "Primary hyperparathyroidism with rare presentation as multiple brown tumours," Clinical Practice, vol. 2, no. 2, p. e48, 2012.

[10] J. S. Silverberg, "Primary hyperparathyroidism," in Primer on the Metabolic Bone Diseases and Disorders of Mineral Metabolism, C. J. Rosen, Ed., pp. 543-552, Wiley-Blackwell, Ames, IA, USA, 8th edition, 2013.

[11] M. D. Walker, M. Rubin, and S. J. Silverberg, "Nontraditional manifestations of primary hyperparathyroidism," Journal of Clinical Densitometry, vol. 16, no. 1, pp. 40-47, 2013.

[12] A. A. Khan, D. A. Hanley, R. Rizzoli et al., "Primary hyperparathyroidism: review and recommendations on evaluation, diagnosis, and management. A Canadian and international consensus," Osteoporosis International, vol. 28, no. 1, pp. 1-19, 2017.

[13] M. Hussain and M. Hammam, "Management challenges with brown tumor of primary hyperparathyroidism masked by severe vitamin D deficiency: a case report," Journal of Medical Case Reports, vol. 10, pp. 166-172, 2016.

[14] H.-K. Sia, M.-C. Hsieh, L.-H. Yang, and S.-T. Tu, "Maxillary brown tumor as initial presentation of parathyroid adenoma: a case report," The Kaohsiung Journal of Medical Sciences, vol. 28, no. 7, pp. 400-403, 2012.

[15] R. Vaishya, A. K. Agarwal, H. Singh, and V. Vijay, "Multiple "Brown Tumors" Masquerading," Cureus, vol. 7, no. 12, p. e431, 2015.

[16] R. Huang, R. Zhuang, Y. Liu, T. Li, and J. Huang, "Unusual presentation of primary hyperparathyroidism: report of three cases," BMC Medical Imaging, vol. 15, pp. 23-28, 2015.

[17] J. S. Keyser and G. N. Postma, "Brown tumor of the mandible," American Journal of Otolaryngology, vol. 17, no. 6, pp. 407-410, 1996.

[18] D. Gulati, V. Bansal, P. Dubey, S. Pandey, and A. Agrawal, "Central giant cell granuloma of posterior maxilla: first expression of primary hyperparathyroidism," Case Reports in Endocrinology, vol. 2015, Article ID 170412, 7 pages, 2015.

[19] A. Casteràs, L. Darder, C. Zafon et al., "Brown tumor of the jaw after pregnancy and lactation in a MEN1 patient," Endocrinology, Diabetes \& Metabolism Case Reports, vol. 2016, 2016.

[20] F. A. Qari, "Brown tumor in a patient with ectopic mediastinal parathyroid adenoma: a case report," The Saudi Dental Journal, vol. 26, no. 2, pp. 74-77, 2014.

[21] E. Ullah, M. Ahmad, S. A. Ali, and N. Redhu, "Primary hyperparathyroidism having multiple Brown tumors mimicking malignancy," Indian Journal of Endocrinology and Metabolism, vol. 16, no. 6, pp. 1040-1042, 2012.

[22] T. Kalathas, T. Kalatha, and E. Boultoukas, "Brown tumors; a possible pitfall in diagnosing metastatic disease," Hellenic Journal of Nuclear Medicine, vol. 13, no. 1, pp. 15-17, 2010. 
[23] D. Rao, A. Kalappanavar, and R. Annigeri, "Normocalcemic hyperparathyroidism manifesting as brown tumor of mandible: a case report," Journal of Orofacial Sciences, vol. 8, no. 1, pp. 71-73, 2016.

[24] L. Kalapala, S. Keerthi sai, S. Babburi et al., "An endocrine jaw lesion: dentist perspective in diagnosis," Case Reports in Dentistry, vol. 2016, Article ID 2582038, 5 pages, 2016.

[25] P. F. Pechalova and E. G. Poriazova, "Brown tumor at the jaw in patients with secondary hyperparathyroidism due to chronic renal failure," Acta Medica (Hradec Kralove, Czech Republic), vol. 56, no. 2, pp. 83-86, 2013.

[26] N. Soundarya, N. Sharada, G. Prakash, and G. Pradeep, "Bilateral maxillary brown tumors in a patient with primary hyperparathyroidism: report of a rare entity and review of literature," Journal of Oral and Maxillofacial Pathology, vol. 15, no. 1, pp. 56-59, 2011.

[27] H. Zou, L. Song, M. Jia et al., "Brown tumor of multiple facial bones associated with primary hyperparathyroidism," Medicine (Baltimore), vol. 97, no. 33, Article ID e11877, 2018.

[28] D. Popovik-Monevska, S. Bozovik-Dvojakovska, V. Popovski, A. Benedetti, A. Grchev, and F. Koneski, "Brown tumour in the mandible and skull osteosclerosis associated with primary hyperparathyroidism-a case report," Open Access Macedonian Journal of Medical Sciences, vol. 6, no. 2, pp. 406-409, 2018.

[29] K. Verma, D. Verma, N. Patwardhan, and P. Verma, "Craniofacial brown tumor as a result of secondary hyperparathyroidism in chronic renal disease patient: a rare entity," Journal of Oral and Maxillofacial Pathology, vol. 18, no. 2, pp. 267-270, 2014.

[30] A. L. S. Guimarães, L. Marques-Silva, and C. C. Gomes, W. H. Castro, R. A. Mesquita, and R. S. Gomez, Peripheral brown tumour of hyperparathyroidism in the oral cavity," Oral Oncology Extra, vol. 42, no. 3, pp. 91-93, 2006.

[31] S. Artul, A. Bowirrat, M. Yassin, and Z. Armaly, "Maxillary and frontal bone simultaneously involved in brown tumor due to secondary hyperparathyroidism in a hemodialysis patient," Case Reports in Oncological Medicine, vol. 2013, Article ID 909150, 4 pages, 2013.

[32] R. Carvalho, S. Kurochka, J. Rocha, and J. S. Fernandes, "Brown tumor of the mandible: magnetic susceptibility demonstrated by MRI," Radiology Case Reports, vol. 7, no. 2, p. 662, 2015.

[33] J. Zhang, H. Wang, W. Tian, Q. He, and M. Zhu, "Brown tumor of the rib as a first presentation of primary hyperparathyroidism: report of three cases and literature review," Thoracic Cancer, vol. 4, no. 4, pp. 474-478, 2013.

[34] S. S. Ojha, J. Valecha, A. Sharma, and R. Nilkanthe, "Role of fine needle aspiration cytology in diagnosis of brown tumor secondary to parathyroid adenoma," Journal of Laboratory Physicians, vol. 10, no. 1, pp. 118-120, 2018.

[35] J. Fernandez-Sanroman, J. M. Anton-Badiola, and A. CostasLopez, "Brown tumor of the mandible as first manifestation of primary hyperparathyroidism: diagnosis and treatment," Medicina Oral, Patologia Oral y Cirugia Bucal, vol. 10, no. 2, pp. 169-172, 2005.

[36] M. M. Suarez-Cunqueiro, R. Schoen, A. Kersten, J. Klisch, and R. Schmelzeisen, "Brown tumor of the mandible as first manifestation of atypical parathyroid adenoma," Journal of Oral and Maxillofacial Surgery, vol. 62, no. 8, pp. 1024-1028, 2004.

[37] M. Alhusban and Z. H. Baqain, "Mandibular brown tumor as the first manifestation of primary hyperparathyroidism: a case report," The Saudi Dental Journal, vol. 23, no. 2, pp. 107-109, 2011.
[38] J. Pepe, C. Cipriani, R. Pilotto et al., "Sporadic and hereditary primary hyperparathyroidism," Journal of Endocrinological Investigation, vol. 34, no. 7 Suppl, pp. 40-44, 2011.

[39] J. C. Rubinstein, S. K. Majumdar, W. Laskin et al., "Hyperparathyroidism-jaw tumor syndrome associated with largescale 1q31 deletion," Journal of the Endocrine Society, vol. 1, no. 7, pp. 926-930, 2017.

[40] L. Bricaire, M.-F. Odou, C. Cardot-Bauters et al., "Frequent large GermlineHRPT2Deletions in a French national cohort of patients with primary hyperparathyroidism," The Journal of Clinical Endocrinology \& Metabolism, vol. 98, no. 2, pp. E403-E408, 2013.

[41] A. Pichardo-Lowden, A. Manni, B. Saunders, and M. Baker, "Familial hyperparathyroidism due to a germline mutation of theCDC73Gene: implications for management and age-appropriate testing of relatives at risk," Endocrine Practice, vol. 17, no. 4, pp. 602-609, 2011.

[42] P. J. Newey, M. R. Bowl, T. Cranston, and R. V. Thakker, "Cell division cycle protein 73 homolog (CDC73) mutations in the hyperparathyroidism-jaw tumor syndrome (HPT-JT) and parathyroid tumors," Human Mutation, vol. 31, no. 3, pp. 295-307, 2010.

[43] L. Lin, M. Czapiga, L. Nini, J.-H. Zhang, and W. F. Simonds, "Nuclear localization of the parafibromin tumor suppressor protein implicated in the hyperparathyroidism-jaw tumor syndrome enhances its proapoptotic function," Molecular Cancer Research, vol. 5, no. 2, pp. 183-193, 2007.

[44] H. du Preez, A. Adams, P. Richards, and S. Whitley, "Hyperparathyroidism jaw tumour syndrome: a pictoral review," Insights Into Imaging, vol. 7, no. 6, pp. 793-800, 2016.

[45] K. J. Bradley, M. R. Hobbs, I. D. Buley et al., "Uterine tumours are a phenotypic manifestation of the hyperparathyroidismjaw tumour syndrome," Journal of Internal Medicine, vol. 257, no. 1, pp. 18-26, 2005.

[46] Y. Shibata, M. Yamazaki, M. Takei, S. Uchino, A. Sakurai, and M. Komatsu, "Early-onset, severe, and recurrent primary hyperparathyroidism associated with a novel CDC73 mutation," Endocrine Journal, vol. 62, no. 7, pp. 627-632, 2015.

[47] É. Marchiori, B. Isom, and A. Indresano, "Management of ossifying fibroma in a suspicious case of hyperparathyroidjaw tumor syndrome," Craniomaxillofacial Trauma \& Reconstruction, vol. 8, no. 3, pp. 228-233, 2015.

[48] K. J. Bradley and R. V. Thakker, "The HyperparathyroidismJaw Tumour (HPT-JT) Syndrome," Clinical Cases in Mineral and Bone Metabolism, vol. 3, no. 7, pp. 167-174, 2006.

[49] S. Khan, V. Raj, N. Sharma, and T. Sethi, "Ossifying fibroma of maxilla in a male child: report of a case and review of the literature," National Journal of Maxillofacial Surgery, vol. 2, no. 1, pp. 73-79, 2011.

[50] M. A. Ojo, O. F. Omoregie, M. Altini, and H. Coleman, “A clinico-pathologic review of 56 cases of ossifying fibroma of the jaws with emphasis on the histomorphologic variations," Nigerian Journal of Clinical Practice, vol. 17, no. 5, pp. 619623, 2014.

[51] R. Phitayakorn and C. R. McHenry, "Jaw tumor: an uncommon presenting manifestation of primary hyperparathyroidism," World Journal of Endocrine Surgery, vol. 2, no. 1, pp. 45-50, 2010.

[52] A. Ono, G. Tsukamoto, H. Nagatsuka et al., "An immunohistochemical evaluation of BMP-2, -4, osteopontin, osteocalcin and PCNA between ossifying fibromas of the jaws and peripheral cemento-ossifying fibromas on the gingiva," Oral Oncology, vol. 43, no. 4, pp. 339-344, 2007. 
[53] Y. Lianjia, J. Yan, T. Doi, I. Sekine, K. Ogawa, and M. Moril, "Immunohistochemical localization of bone morphogenetic protein (BMP) in calcifying fibrous epulis," Journal of Oral Pathology and Medicine, vol. 22, no. 9, pp. 406-410, 1993.

[54] R. E. Marx and D. Stern, Oral and Maxillofacial Pathology. A Rationale for Diagnosis and Treatment, pp. 789-795, Quintessence, Batavia, IL, USA, 2002.

[55] P. Bhatt, A. Kaushik, V. C. Vinod, K. Sridevi, and A. Chaudhry, "Ossifying fibroma of the maxilla: a rare case," International Journal of Radiology \& Radiation Therapy, vol. 3, no. 2, pp. 198-201, 2017.

[56] F. J. Pimenta, L. F. Gontijo Silveira, G. C. Tavares et al., "HRPT2 gene alterations in ossifying fibroma of the jaws," Oral Oncology, vol. 42, no. 7, pp. 735-739, 2006.

[57] A. C. de Mesquita Netto, R. S. Gomez, M. G. Diniz et al., "Assessing the contribution of HRPT2 to the pathogenesis of jaw fibrous dysplasia, ossifying fibroma, and osteosarcoma," Oral Surgery, Oral Medicine, Oral Pathology and Oral Radiology, vol. 115, no. 3, pp. 359-367, 2013.

[58] Y. Chen, D. Y. Hu, T. T. Wang et al., "CDC73 gene mutations in sporadic ossifying fibroma of the jaws," Diagnostic $\mathrm{Pa}$ thology, vol. 11, no. 1, pp. 91-97, 2016.

[59] T. T. Wang, R. Zhang, L. Wang, Y. Chen, Q. Dong, and T. J. Li, "Two cases of multiple ossifying fibromas in the jaws," $D i$ agnostic Pathology, vol. 9, pp. 75-84, 2014.

[60] M. Iacobone, B. Carnaille, F. F. Palazzo, and M. Vriens, "Hereditary hyperparathyroidism-a consensus report of the European society of endocrine surgeons (ESES)," Langenbeck's Archives of Surgery, vol. 400, no. 8, pp. 867-886, 2015.

[61] A. Maria, Y. Sharma, and M. Malik, "Juvenile ossifying fibroma of mandible: a case report," Journal of Maxillofacial and Oral Surgery, vol. 12, no. 4, pp. 447-450, 2013.

[62] Y. Liu, H. Wang, M. You et al., "Ossifying fibromas of the jaw bone: 20 cases," Dentomaxillofacial Radiology, vol. 39, no. 1, pp. 57-63, 2010.

[63] S. P. Agarwal, S. Kumar, H. P. Singh, and S. A. Usmani, "Huge ossifying fibroma maxilla," National Journal of Maxillofacial Surgery, vol. 6, no. 2, pp. 241-243, 2015.

[64] R. K. Peravali, H. B. Bhat, and S. Reddy, "Maxillo-mandibular cemento-ossifying fibroma: a rare case report," Journal of Oral and Maxillofacial Surgery, vol. 14, no. Suppl 1, pp. S300-S307, 2015.

[65] D. Gopinath, V. T. Beena, G. Sugirtharaj et al., "Cementoossifying fibroma in a patient with end-stage renal disease," Case Reports in Dentistry, vol. 2013, Article ID 923128, 4 pages, 2013.

[66] R. Mithra, P. Baskaran, and M. Sathyakumar, "Imaging in the diagnosis of cemento-ossifying fibroma: a case series," Journal of Clinical Imaging Science, vol. 2, p. 52, 2012.

[67] A. T. Kendi, S. Kara, D. Altinok, and S. Keskil, "Sinonasal ossifying fibroma with fluid-fluid levels on MR images," AJNR. American Journal of Neuroradiology, vol. 24, no. 8, pp. 1639-1641, 2003.

[68] M. d. Andrade, Y. T. C. Silva-Sousa, M. F. T. Marques, M. L. d. A. Pontual, F. M. d. M. Ramos-Perez, and D. E. d. C. Perez, "Ossifying fibroma of the jaws: a clinicopathological case series study," Brazilian Dental Journal, vol. 24, no. 6, pp. 662-666, 2013.

[69] S. Khaji, S. Shah, and M. Baheti, "Ossifying fibroma of the maxilla: an uncommon tumor presenting diagnostic and management dilemma for the clinician: a rare case report," Journal of Dental and Allied Sciences, vol. 3, no. 1, pp. 53-57, 2014.
[70] U. Pal and N. Mishra, "Placement of implants in an ossifying fibroma defect obliterated with demineralized, freeze-dried bone allograft and Plasma-rich growth factor," Contemporary Clinical Dentistry, vol. 3, no. 4, pp. 471-474, 2012.

[71] J. D. Chen, C. Morrison, C. Zhang, K. Kahnoski, J. D. Carpten, and B. T. Teh, "Hyperparathyroidism-jaw tumour syndrome," Journal of Internal Medicine, vol. 253, no. 6, pp. 634-642, 2003.

[72] E. F. McCarthy, "Fibro-osseous lesions of the maxillofacial bones," Head and Neck Pathology, vol. 7, no. 1, pp. 5-10, 2013.

[73] B. W. Nevielle, D. D. Damm, C. M. Allen, and A. C. Chi, Oral \& Maxillofacial Pathology, Elsevier, St. Louis, MO, USA, 4th edition, 2016. 